\title{
Effects of interdisciplinary teamwork on patient-reported experience of cancer care

Dominique Tremblay ${ }^{1,2^{*}}$ (D, Danièle Roberge ${ }^{2,3}$, Nassera Touati ${ }^{4}$, Elizabeth Maunsell ${ }^{5}$ and Djamal Berbiche ${ }^{2}$

\begin{abstract}
Background: Interdisciplinary teamwork (ITW) is deemed necessary for quality cancer care practices. Nevertheless, variation in ITW intensity among cancer teams is understudied, and quantitative evidence of the effect of different ITW intensities among cancer teams on patients' perceived experience of care is limited. This study aims to compare patient-reported experience measures (PREMs) of cancer outpatients followed by teams characterized by high vs. low ITW intensity.

Methods: The study is designed as an ex post facto quasi-experimental study. Participants ( $n=1379)$ were recruited in nine outpatient oncology clinics characterized by different ITW intensities. ITW intensities were evaluated using the characteristics of structure (team composition and size) and process (interactions among team members), as per West's seminal work on team effectiveness. ITW intensity was dichotomized (high vs. low ITW intensity). PREMs were classified and measured using validated scales corresponding to six dimensions: Prompt access to care, Person-centred response, Quality of patient-professional communication, Quality of the care environment, Continuity of care, and Results of care. Dichotomous variables were created for each dimension (positive vs. less positive experience). Multiple logistic regression analyses were performed to assess the association between ITW intensities and the six PREMs dimensions, while controlling for patient and organizational characteristics. PROC GENMOD was used to fit logistic models for categorical variables.

Results: Outpatients treated by teams characterized by high ITW intensity reported almost four times more positive perceptions of Prompt access to care compared to patients treated by low ITW intensity teams $(\mathrm{OR}=3.99 ; \mathrm{Cl}=1.89-8.41)$. High ITW intensity also positively affected patients' perceptions of Quality of patient-professional communication (OR=2.37; $\mathrm{Cl}=1.25-4.51)$, Person-centred response $(\mathrm{OR}=2.11 ; \mathrm{Cl}=1.05-4.24]$, and Continuity of care $(\mathrm{OR}=2.18 ; \mathrm{Cl}=1.07-4.45)$. No significant association was found between ITW intensity and perceived Results of care $(\mathrm{OR}=1.31 ; \mathrm{Cl}=0.68-2.52)$ or Quality of the care environment $(\mathrm{OR}=0.66 ; \mathrm{Cl}=0.31-1.39)$.
\end{abstract}

Conclusions: This study provides empirical evidence, from the patient's perspective, that ITW intensity affects some critical aspects of patient-reported quality of care. Future research will allow explaining how and why ITW structure and processes may contribute to positive cancer care experiences.

Keywords: Cancer care, Interdisciplinary teamwork, Patient care team, Patient-reported experience measures, Quasi-experimental study

\section{Background}

Interdisciplinary teamwork (ITW) is recognized as a gold standard for the management of cancer patients and is promoted by leading organizations such as the European Partnership for Action Against Cancer (EPAAC) [1] and the American Society of Clinical Oncology (ASCO) [2].

\footnotetext{
* Correspondence: dominique.tremblay2@usherbrooke.ca

${ }^{1}$ Nursing School, Faculty of Medicine and Health Sciences, Université de Sherbrooke, Longueuil, Quebec, Canada

${ }^{2}$ Charles-Le Moyne Hospital Research Center, Greenfield Park, Quebec, Canada Full list of author information is available at the end of the article
}

Given the multiple potential benefits and the goal of providing all patients with comprehensive care, ITW represents both a rational and ethical approach to care. ITW involves health care professionals working as a team with the purpose of discussing individual cases and recommending care plans. Teamwork has been defined in several ways. The definition of ITW used in this article involves an alliance of all medical and health care professionals related to a specific tumor site. Their approach to cancer care is guided by their willingness to agree on 
evidence-based clinical decisions and to deliver coordinated care throughout the cancer care continuum, while patients are encouraged to take an active role in their care [1]. This definition relates to specific aspects of cancer care and is similar to those used in the general health care sector [3, 4]. Typically, interdisciplinary cancer care teams include clinicians specialized in oncology, pathology, pharmacology, and psychosocial and nursing care in an oncology setting. Other relevant professionals with training that is not specific to oncology may also be part of the cancer care team [5].

Recent systematic reviews have supported the rationale for ITW as a way to improve cancer patient outcomes and survival, notably with respect to clinical benefits based on personalized health care decisions [5-7]. Despite these encouraging observations, in-depth appraisal of the quality of evidence raises concerns about inferring a direct causal relationship between ITW and patient experience [8]. First, the description of health care teams has been incomplete and, as a result, the operationalization of ITW concepts and measures has been inconsistent $[7,9]$. Second, the heterogeneity of interventions considered as ITW (including "comprehensive cancer team," "tumor board," and "multidisciplinary cancer conference"), and outcomes used to assess the effects of ITW, makes it impossible to generalize the results or identify ITW key elements that affect patient-reported experience measures [10]. For example, cancer care resulting from ITW focusing on pathology may produce different effects than ITW focusing on psychosocial aspects, quality of life, patient empowerment, and patient rights. Third, although the most effective way to test the effects of ITW would be to conduct a large, parallel-group, randomized controlled trial (RCT), such a research design is impossible given that ITW has already been implemented to varying degrees and that its implementation is critically dependent on context [11]. Moreover, an RCT could not be validly conducted given that most cancer team members naturally work together to face the complexity of cancer care. Finally, most studies aimed at determining the effect of teamwork have focused on patient outcomes or patient satisfaction and not on PREMs dimensions. While this type of evaluation provides useful insight into patients' perception of services against their expectations, it offers little information on the actual processes at play during active care. These observations indicate uncertainty about the association between ITW and patient perception of their care experience [12, 13]. Such evidence nonetheless suggests the following hypothesis: the greater the intensity of ITW in cancer care teams, the more extensive the beneficial effects perceived by patients. This study aims to compare ITW intensity with PREMs dimensions of care among cancer outpatients.

\section{Conceptual framework}

Our group developed a conceptual framework [12] that was adapted to guide the study. We constructed our framework (Fig. 1) based on a review of the relevant scientific and grey literature to ensure systematic identification of the most critical ITW indicators. It was constructed using commonly accepted structure-process-outcome associations, building on the work of West et al. [14-16]. The framework illustrates the convergence of structure

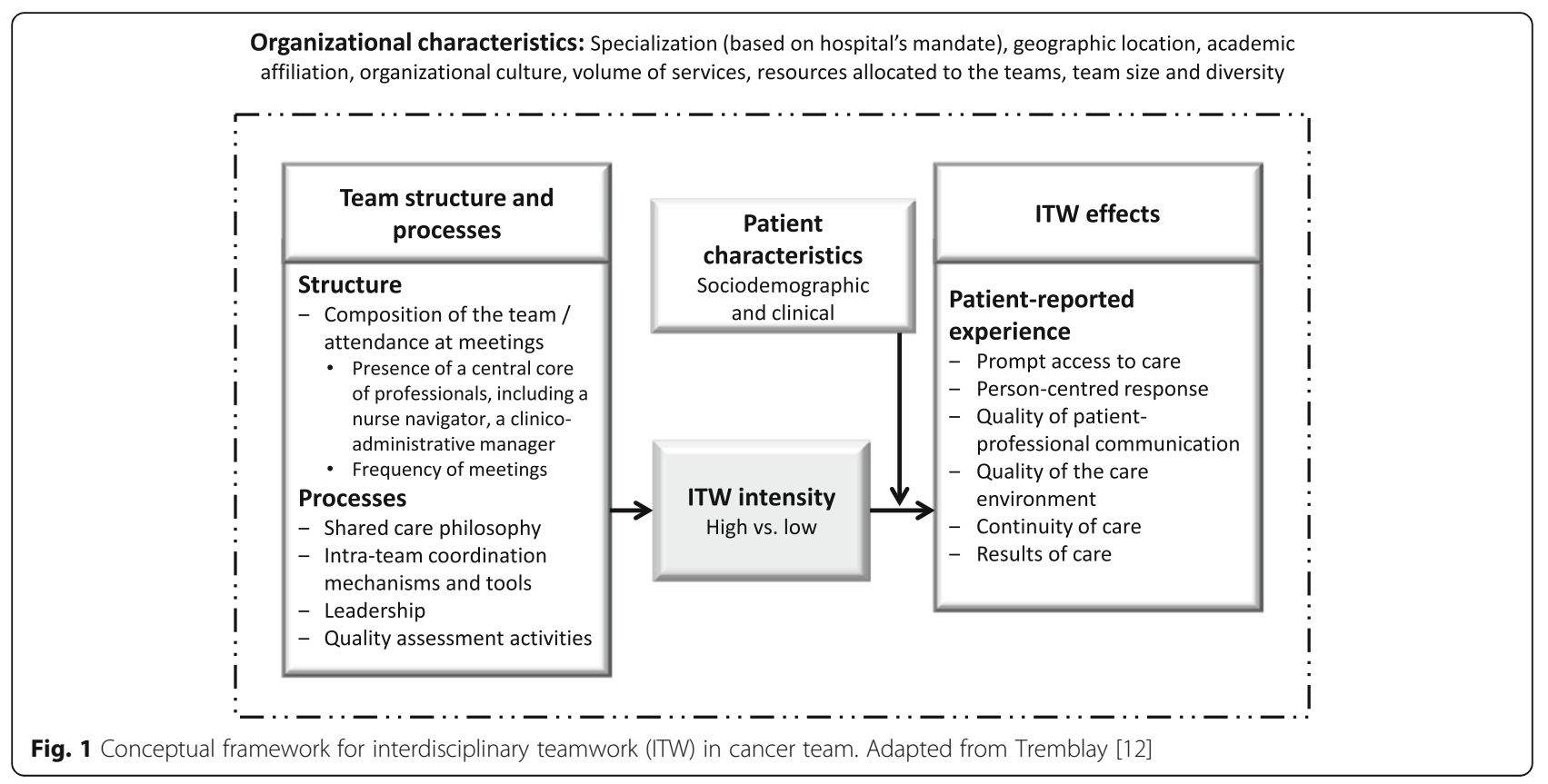


and process characteristics that affect ITW intensity. Structure characteristics include composition of the team (suggested by both the scientific literature and the Quebec cancer program); attendance at team meetings by team members (central professional core, nurse navigator, clinical-administrative manager); and frequency of meetings. Process characteristics include shared philosophy of care (extent to which values, goals, and objectives are shared by team members); intra-team coordination mechanisms and tools (presence of a cancer care coordinator, also known as oncology pivot nurse or nurse navigator/coordinator); leadership (involving both the physician and front-line manager); and quality assessment activities (including continuing education opportunities for gaining new knowledge and sharing expertise, and systems for capturing patient satisfaction). In this study, it is hypothesized that high ITW intensity is associated with PREMs corresponding to positive patient perception of the following dimensions of cancer care: Prompt access to care, Person-centred response, Quality of patient-professional communication, Quality of the care environment (basic amenities and professional courtesy), Continuity of care, and Results of care. The framework also shows that the characteristics of cancer patients and the organizational context of cancer teams may affect ITW intensity and thus ultimately the patient's perceived experience. Similarly, the characteristics of cancer patients may influence their perception of the dimensions of care.

\section{Study context}

The study was conducted in the Province of Quebec, Canada. The province has a publicly funded health care system providing universal access to medical services for over eight million residents. Quebec's initial cancer control plan was launched in 1998 to enhance the accessibility, coordination, continuity, and responsiveness of patientcentred care [17]. Among other things, the plan prioritized service reorganization by defining and designating local, regional, and supra-regional mandates for all hospital cancer teams. Regional and supra-regional mandates are differentiated in terms of their degree of specialization of cancer services, the radiotherapy they provide, and their consulting role. The plan provides explicit guidelines for team structure and processes and proposes a number of initiatives to strengthen the functioning of all local cancer teams $(n=65)$. These include continuing education programs for interprofessional collaboration, a description of care coordinator tasks and responsibilities, and an accreditation process for cancer teams. Quebec's cancer control plan defines local teams as a core of professionals including at least a pivot nurse, a pharmacist, a medical oncologist, a nutritionist, and a social worker or psychologist [18]. The team's size and diversity are determined according to the clients' needs and the caseload of the cancer outpatient clinic. Cancer team processes should involve the following: initial assessment of patient needs from a holistic perspective; formal and regular interdisciplinary meetings to discuss complex patient-family biopsychosocial problems; development of coordinated interdisciplinary intervention plans; mastery of coordination procedures both upstream and downstream, supported by appropriate tools within the team and with external partners; and implementation of measures to ascertain the quality of the services offered. The overarching goal is to provide comprehensive cancer care and treatments to patients who come to the oncology clinics for investigative examinations, chemotherapy, or follow-up visits.

\section{Methods}

\section{Study design and procedures}

Our cross-sectional study used an ex post facto quasiexperimental design [19] to investigate potential associations by observing an existing condition (ITW in our case) and to evaluate the association between ITW intensity and the experience of care as reported by outpatients. According to Cohen et al., this design was deemed appropriate considering that ITW already occurred among cancer team members and that this variable is studied in retrospect for seeking the likely effects that the changes in this independent variable (High vs. Low ITW intensity) produce on a set of dependent variables (PREMs) [19].

\section{ITW intensity measure}

To our knowledge, no validated tool was available to evaluate ITW intensity in oncology teams at the time we undertook the study $[20,21]$. We developed an ITW intensity measure based on our structure-process-outcome conceptual framework. A list of potential qualitative indicators was then submitted to a group of nine experts including clinicians, managers, and researchers to test the content validity of our ITW intensity measure from both scientific and pragmatic points of view [22]. The resulting consensus led to a tool that included thirteen items grouped into five components (Fig. 1): 1) Composition of the team and frequency of cancer care team meetings (two items); 2) Shared care philosophy among team members (one item); 3) Coordination mechanisms and tools (three items); 4) Leadership, responsibilities, and processes shared among clinicians and managers (two items); 5) Quality assessment activities (five items). An assessment grid covering all of these dimensions was pre-tested in nine well-known clinics that had previously participated in our studies on cancer care transformation [23-26]. It was then administered by a member of the research team during an individual interview with the cancer clinic first-line manager. Structured response to items in the key informant interview was converted into quantifiable categories according to the seminal article by Caracelli and Green [27]. For each item (13), a score was created; the scores were then equally 
weighted and converted to a final ITW intensity score ranging from 0 to 10 . Interview grid and quantification criteria are described in Additional file 1.

\section{Study settings and participants}

The selection of study settings resulted from a stepwise strategy. An initial ITW score from all the outpatient oncology clinics in Quebec with a local or a regional mandate $(n=65)$ was established using the Ministry of Health and Social Services administrative database for monitoring the structure and processes of cancer care teams.

For feasibility reasons, clinics with very low patient volume were excluded. Clinics with the six highest and six lowest ITW scores were selected for a total of twelve clinics. Among these clinics, nine agreed to participate in the study, representing nearly $14 \%$ of all outpatient oncology clinics $(n=65)$ with a local or a regional mandate in Quebec (Table 1). Second, the data were collected from managers in each participating clinic using the ITW tool developed for the present study. Third, the outpatient clinics samples were divided into two categories: Low ITW intensity and High ITW intensity. Three clinics were classified as Low ITW intensity (scores ranging from 4.08 to 6.17), and six were classified as High ITW intensity (scores ranging from 7.88 to 9.75 ) (Table 1). A cut-off point was determined to maximize differences in ITW intensities when comparing participating sites. Greater score differences between ITW intensities were seen in relation to team process characteristics compared to team structure characteristics.

Participants were recruited from the participating outpatient oncology clinics between October 2010 and November 2011. Minimal criteria were applied to maximize patient eligibility [28] and to increase the likelihood that participants would broadly represent cancer patients both seeking care in these outpatient clinics and having a minimal experience of care received from a team. Thus, patients were eligible if they were 18 years of age or over, had a confirmed cancer diagnosis (all cancers, all stages), had visited the oncology clinic at least once in the preceding twelve months, and could read and understand either French or English. All participants were recruited upon arrival at the oncology clinic whether for investigative examinations, chemotherapy, or follow-up visits.

Designated staff members were trained to identify participants who met our inclusion criteria and to provide them with information about the study in a standardized way. Patients interested in the study were given the following material: a cover letter describing the study and outlining the conditions if they agreed to participate; a self-administered survey questionnaire; and a stamped envelope to return the completed questionnaire by mail. Weekly contact with designated staff members and a reminder about the study was sent to patients two weeks after initial distribution of the questionnaire to improve response rate [29]. Participation in the survey was voluntary and anonymous.

\section{Patient-reported experience questionnaire}

The questionnaire included thirty-three items grouped into six scales considered to measure the anticipated effects of ITW on the patients' experience of cancer care. Four out of six cancer-adapted scales were derived from the Frenchlanguage version of the Health System Responsiveness Questionnaire [30], validated by Tremblay et al. [26, 31]: Prompt access to care (four items; $\alpha=0.77$ ), Person-centred response (five items; $\alpha=0.67$ ), Quality of patient-professional communication (five items; $\alpha=0.85$ ), and Quality of the care environment (five items; $\alpha=0.64$ ). The Continuity of care scale (nine items; $\alpha=0.77$ ) was derived from a generic measure of continuity aiming to assess information gaps perceived by patients encountering several professionals [32]. The Results of care scale (five items; $\alpha=0.82$ ) was

Table 1 Organizational characteristics of participating sites $(N=9)$

\begin{tabular}{|c|c|c|c|c|c|c|c|}
\hline \multirow[t]{2}{*}{ Site } & \multirow[t]{2}{*}{ Mandate $^{a}$} & \multirow{2}{*}{$\begin{array}{l}\text { Geographic } \\
\text { location }\end{array}$} & \multirow{2}{*}{$\begin{array}{l}\text { Academic- } \\
\text { affiliation }\end{array}$} & \multirow{2}{*}{$\begin{array}{l}\text { Cancer team } \\
\text { size }^{b}\end{array}$} & \multirow{2}{*}{$\begin{array}{l}\text { ITW } \\
\text { intensity }\end{array}$} & \multicolumn{2}{|c|}{ Participants $^{c}$} \\
\hline & & & & & & $\bar{N}$ & (\%) \\
\hline A & Regional & Rural & Yes & Small & 4.08 & 158 & $(11.5)$ \\
\hline B & Regional & Urban & Yes & Large & 4.71 & 202 & $(14.6)$ \\
\hline$C$ & Regional & Semi-rural & Yes & Large & 6.17 & 158 & (11.5) \\
\hline D & Local & Rural & No & Small & 7.88 & 98 & (7.1) \\
\hline$E$ & Local & Rural & No & Small & 8.13 & 86 & $(6.2)$ \\
\hline $\mathrm{F}$ & Regional & Semi-rural & No & Large & 8.38 & 140 & $(10.2)$ \\
\hline G & Local & Rural & Yes & Small & 9.13 & 143 & $(10.4)$ \\
\hline $\mathrm{H}$ & Local & Urban & Yes & Small & 9.50 & 214 & $(15.5)$ \\
\hline I & Local & Urban & No & Large & 9.75 & 180 & $(13.1)$ \\
\hline Total & & & & & & 1379 & $(100.0)$ \\
\hline
\end{tabular}

${ }^{\mathrm{a}}$ At the time of the study

bLarge: cancer team with 8 or more professionals from various discipline; Small: fewer than 8 such professionals

'Participants with completed questionnaires included for the statistical analysis 
adapted from an instrument measuring perception of primary care services [33]. For all items, patients were asked to report their experience of care within the preceding twelve months using a four-point Likert scale $(1=$ never, $2=$ sometimes, $3=$ often, $4=$ always). Scale scores were calculated as the average rating of all scale items. Thus, scores could vary between 1 and 4, with high scores indicating a more positive perception of cancer care.

Data were also collected on patient and organizational characteristics that could independently affect patient perception of the care experience [34, 35]. Patient sociodemographic characteristics were gender, age, education level, perceived financial situation, self-assessed health status, and perceived emotional distress (reverse-scored). Emotional distress was assessed using the six items from the Health Education Impact Questionnaire (heiQ) [36]. This scale is an adapted and validated French version for a cancer clientele [37, 38], measuring overall negative affective responses in relation to the impact of the illness. Variables related to self-reported patient clinical characteristics at time of recruitment were as follows: time since diagnosis, cancer site, treatment type, and presence of comorbidity.

Organizational characteristics were as follows: hospital mandate regarding oncology services (local or regional); university or non-university affiliated hospital; geographic location (urban, semi-rural, rural); and interdisciplinary team size and diversity (large $=$ eight or more professionals from various disciplines; small $=$ fewer than eight such professionals) $[39,40]$. The patient questionnaire was available in French and English. The Quebec Ministry of Health and Social Care administrative database and oncology team managers were the main sources of information for organizational characteristics.

\section{Statistical analyses}

Statistical analyses were performed using IBM SPSS Statistics 19.0 for Windows and SAS 9.2 for Windows. Descriptive statistics were computed for each questionnaire item and scale score. Since the distribution of PREM dimension scores were skewed toward higher values, these variables were dichotomized [41]. A dichotomous outcome variable was then created in which participants providing positive responses for more than $75 \%$ of a scale's items (e.g., 3 out of 4 items: 4 out of 5 items) were classified as having a positive perceived experience (often, always), while the remainder were classified as having a less positive experience (never, sometimes) [41].

To test the association between ITW intensities and specific dimensions of patient-reported experience, each scale was considered separately as a dependent variable using logistic regression analysis. Because of correlated patient responses within sites, PROC GENMOD was used to fit logistic models. An odds ratio (OR) and a 95\% confidence interval (CI) were calculated to measure the association between ITW intensities and each dependent variable. As per the Strobe Statement on observational studies [42], OR is the ratio of the odds of reporting a positive care experience among patients in high ITW intensity settings, compared to the corresponding figure among patients in low ITW intensity settings. The other patients, as well as organizational characteristics likely to affect patient-reported experience independently of ITW, were simultaneously entered into the multiple logistic regression to obtain an adjusted OR. Potential confounders [42] related to patient factors (gender, age, education level, perceived health status, emotional distress) and to organizational factors (mandate, geographic location, university affiliation, and cancer team size) were included in the final regression analysis.

\section{Results}

Response rate and baseline patient characteristics

Of the eligible patients $(n=1981)$ who were offered the questionnaire, 165 (9.0\%) declined. Of the 1816 who agreed to receive the questionnaire, $1453(80 \%)$ returned it by mail. A total of 1379 participants completed at least $80 \%$ of the items and were included in the analysis, for a response rate of $70 \%$. The response rate in each site was similar and across high and low ITW intensity aggregates.

Table 2 presents patient sociodemographic and clinical characteristics. It also illustrates statistical differences between high and low ITW intensity aggregates. The mean age of the sample was 61 , and the majority of participants were female. About $18 \%$ had completed primary school only. The most frequent cancer types were breast (26.5\%), colorectal $(21.4 \%)$, hematopoietic (15.9\%), and bronchopulmonary (14.2\%). Finally, 55.7\% reported that they were consulting for a cancer diagnosed within the past year, and almost 90\% said they had received chemotherapy in the past year, either alone or in combination with other treatments (surgery and/or radiotherapy).

\section{Patients' overall perception of their care experience}

In general, patients reported positive perceptions of the various aspects of their care experience, with scores ranging from 3.34 $(\mathrm{SD}=0.69)$ to $3.75(\mathrm{SD}=0.01)$ out of 4 for all scales (Table 3). The proportion of patients reporting a positive perception of their experience was also high for most scales (ranging from 64.6 to $75.5 \%$ ) except for Prompt access to care (45.3\%) (Table 4).

Associations between high ITW intensity and dimensions of care are reported in Table 4, which shows adjusted OR. Only Prompt access to care was positively associated with high ITW intensity when unadjusted OR was calculated. After adjusting the multiple regression model for potential confounders related to patient and organizational factors, four of the six dimensions of care showed significant positive associations characterized by 
Table 2 Patient sociodemographic and clinical characteristics $(N=1379)$

\begin{tabular}{|c|c|c|c|c|}
\hline \multirow[t]{2}{*}{ Characteristics } & Full sample & Low ITW & High ITW & \multirow{2}{*}{$\begin{array}{l}\mathrm{Chi}^{2} \text { or } \\
\text { T-test } \\
p \text {-value }\end{array}$} \\
\hline & Percent $\mathrm{n}^{\mathrm{a}}$ & Percent $n^{a}$ & Percent $n^{a}$ & \\
\hline
\end{tabular}

\begin{tabular}{llllllll}
\hline $\begin{array}{l}\text { Gender } \\
\text { Female }\end{array}$ & 61.9 & 845 & 63.8 & 305 & 60.9 & 540 & 0.288 \\
Age (years) & & & & & & & \\
Mean age (SD) & $61.0(11.0)$ & $61.3(10.8)$ & $61.0(12.2)$ & 0.597 \\
$18-49$ & 15.7 & 214 & 13.6 & 65 & 16.8 & 149 & 0.076 \\
$50-69$ & 61.5 & 839 & 65.5 & 313 & 59.3 & 526 & \\
$70-98$ & 22.9 & 312 & 20.9 & 100 & 23.9 & 212 &
\end{tabular}

Education level (completed)

$\begin{array}{llllllll}\text { Primary } & 18.3 & 246 & 18.1 & 85 & 18.4 & 161 & 0.034 \\ \text { Secondary } & 44.4 & 598 & 45.7 & 215 & 43.8 & 383 & \\ \begin{array}{l}\text { Business } \\ \text { college/ }\end{array} & 15.7 & 211 & 18.5 & 87 & 14.2 & 124 & \\ \begin{array}{l}\text { CEGEP } \\ \text { University }\end{array} & 21.6 & 291 & 17.8 & 84 & 23.7 & 207\end{array}$

Perceived financial status

$\begin{array}{lccccccc}\begin{array}{l}\text { Financially } \\ \text { comfortable }\end{array} & 21.9 & 291 & 19.6 & 90 & 23.2 & 201 & 0.155 \\ \text { Earn enough } & 57.0 & 757 & 60.4 & 278 & 55.2 & 479 & \\ \text { Poor } & 18.8 & 249 & 18.5 & 85 & 18.9 & 164 & \\ \text { Very poor } & 2.3 & 31 & 1.5 & 7 & 2.8 & 24 & \\ \text { Cancer type } & & & & & & & \\ \text { Breast } & 26.5 & 359 & 29.1 & 138 & 25.0 & 221 & <0.0001 \\ \text { Colorectal } & 21.4 & 290 & 23.2 & 110 & 20.4 & 180 & \\ \text { Hematopoietic } & 15.9 & 216 & 9.9 & 47 & 19.1 & 169 & \\ \text { Bronchopulmonary } & 14.2 & 192 & 17.5 & 83 & 12.3 & 109 & \\ \text { Female genital } & 4.6 & 62 & 5.7 & 27 & 4.0 & 35 & \\ \text { Other } & 17.5 & 238 & 14.6 & 69 & 19.1 & 169 & \end{array}$

Time since diagnosis (years)

$\begin{array}{llllllll}<1 & 55.7 & 759 & 57.3 & 271 & 54.8 & 488 & 0.003 \\ 1 \text { to } 3 & 27.7 & 377 & 30.7 & 145 & 26.1 & 232 & \\ \geq 3 & 16.7 & 227 & 12.1 & 57 & 19.1 & 170 & \end{array}$

Treatment type

$\begin{array}{llllllll}\begin{array}{l}\text { Chemotherapy } \\ \text { only }\end{array} & 39.0 & 519 & 36.6 & 173 & 40.3 & 346 & <0.0001 \\ \begin{array}{l}\text { Chemotherapy } \\ \text { +other } \\ \text { treatment }\end{array} & 49.0 & 653 & 55.8 & 264 & 45.3 & 389 & \\ \begin{array}{l}\text { Other } \\ \text { None }\end{array} & 6.8 & 91 & 5.7 & 27 & 7.5 & 64 & \\ & 5.1 & 68 & 1.9 & 9 & 6.9 & 59\end{array}$

Health status (self-assessed)

$\begin{array}{llllllll}\text { Good } & 50.4 & 683 & 50.1 & 237 & 50.6 & 446 & 0.871 \\ \text { Poor } & 49.6 & 672 & 49.9 & 236 & 49.4 & 436 & \end{array}$

Table 2 Patient sociodemographic and clinical characteristics $(N=1379)$ (Continued)

Comorbidities (self-reported)

$\begin{array}{llllllll}0 & 34.3 & 473 & 33.7 & 162 & 34.6 & 311 & 0.891 \\ 1 \text { to 3 } & 59.4 & 819 & 59.7 & 287 & 59.2 & 532 & \\ \text { More than 3 } & 6.3 & 87 & 6.7 & 32 & 6.1 & 55 & \end{array}$

Emotional distress ${ }^{c}$

\begin{tabular}{llllllll} 
Low & 47.7 & 647 & 51.1 & 241 & 46.0 & 406 & 0.075 \\
High & 52.3 & 708 & 48.9 & 231 & 54.0 & 477 & \\
\hline
\end{tabular}

${ }^{a} n$ may vary per characteristic due to missing value

$\mathrm{b}_{\text {In }}$ Quebec, business colleges and CEGEPs are post-secondary institutions providing pre-university education (2 years) or specialized vocational programs (3 years)

${ }^{\mathrm{c}}$ Form heiQ emotional distress score (6 items), Low: lower than mean (normal distribution); High: higher than mean

high ITW intensity. The strongest association was found with Prompt access to care ( $\mathrm{OR}=3.99$; $\mathrm{CI}=1.89-8.41)$. Quality of patient-professional communication was more than two times positively associated with high ITW intensity $(\mathrm{OR}=2.37 ; \mathrm{CI}=1.25-4.51)$, followed by Continuity of care $(\mathrm{OR}=2.18 ; \mathrm{IC}=1.07-4.45)$ and Personcentred response $(\mathrm{OR}=2.11$; $\mathrm{IC}=1.05-4.24)$. No significant association was found between ITW intensity and Results of care (OR $=1.31 ; \mathrm{CI}=0.68-2.52)$ or Quality of the care environment $(\mathrm{OR}=0.66 ; \mathrm{CI}=0.31-1.39)$.

\section{Discussion}

This study aimed to compare ITW intensity with PREM dimensions of care among cancer outpatients. The results show that cancer patients treated in outpatient clinics characterized by high ITW intensity are more likely to report positive perceptions regarding four PREMs dimensions (Prompt access to care, Person-centred response, Quality of patient-professional communication, and Continuity of care), compared to patients treated in clinics with low ITW intensity. The results thus support the hypothesis whereby higher ITW intensity within cancer care teams translates into a more positive patient perception of their care experience.

Table 3 Description of the six dimensions of patient-reported experience

\begin{tabular}{lcc}
\hline Dimension & Mean score $^{\mathrm{a}}$ & $\mathrm{SD}^{\mathrm{b}}$ \\
\hline Prompt access to care & 3.34 & 0.69 \\
Person-centred response & 3.66 & 0.41 \\
Quality of patient-professional communication & 3.65 & 0.56 \\
Quality of the care environment & 3.72 & 0.37 \\
Continuity of care & 3.75 & 0.01 \\
Results of care & 3.60 & 0.55 \\
\hline
\end{tabular}

aTheoretical score range: 1 to 4; higher scores indicate more positive perception of experience

${ }^{b} \mathrm{SD}$ : Standard deviation 
Table 4 Association between interdisciplinary teamwork intensity and the dimensions of patient-reported experience measures (PREMs) $^{\mathrm{a}}$

\begin{tabular}{llll}
\hline $\begin{array}{l}\text { Dimensions of patient- } \\
\text { reported experience }\end{array}$ & $\begin{array}{l}\text { Positive PREMs } \\
\text { (Overall \%) }\end{array}$ & $\begin{array}{l}\text { Adjusted }^{c} \\
\mathrm{OR}^{\mathrm{b}}(95 \% \mathrm{Cl})\end{array}$ & $p$ value \\
\hline $\begin{array}{l}\text { Prompt access to care } \\
\begin{array}{l}\text { Quality of patient- } \\
\text { professional } \\
\text { communication }\end{array}\end{array}$ & $(45.3)$ & $3.99(1.89-8.41)$ & 0.0002 \\
$\begin{array}{l}\text { Continuity of care } \\
\begin{array}{l}\text { Person-centred } \\
\text { response }\end{array}\end{array}$ & $(75.5)$ & $2.37(1.25-4.51)$ & 0.0325 \\
$\begin{array}{l}\text { Results of care } \\
\begin{array}{l}\text { Quality of the care } \\
\text { environment }\end{array}\end{array}$ & $(73.4)$ & $2.18(1.07-4.45)$ & 0.0324 \\
\hline
\end{tabular}

a Low ITW intensity is the reference

${ }^{\mathrm{b}} \mathrm{OR}$ : odds ratio

'Adjusted for patient characteristics (health status, age, gender, education level, emotional distress) and organizational characteristics

\section{ITW intensity variation}

The current literature on cancer teams focuses on their objectives and their organization [6] or on team effectiveness [5], and it does not integrate teamwork components into proper structure-process-outcome associations. Our ITW tool administered through interview with front-line manager provided original data not only on team structure (Composition of the team, Frequency of cancer care team meetings) but also on critical aspects of the teaming processes (Shared care philosophy among team members, Coordination mechanisms and tools, Leadership, Responsibilities and processes shared among clinicians and managers, Quality assessment activities). Those results are consistent with the work of Salas et al. who developed a comprehensive model for enhancing teamwork skills in healthcare (i.e., The Big Five in Teamwork [43]). Although the ITW tool is in its infancy, it allowed revealing variation in ITW intensity and its association with cancer patient experience.

\section{Patient-reported experience}

To the best of our knowledge, and considering reviews in the field of interdisciplinary teamwork and patient-reported outcomes, our study is one of the few to demonstrate the extent to which positive patient perception of Prompt access to care is associated with high ITW intensity within care teams [5-7]. Positive patient perception of Prompt access to care is an important anticipated effect of high ITW intensity. Indeed, access to cancer care from first symptoms to treatment is a topic of concern for researchers and policy makers [44-47]. In our study, Prompt access to care was defined as patients' perception of their ability to reach or see an oncology professional, as required, at various times of the day and on different days of the week. Outpatients, who are by definition outside the hospital setting, must employ a number of self-management strategies to cope with their cancer symptoms and treatment. When these coping strategies fail, the patients' unmet needs may require prompt access to care professionals [48]. A possible explanation of the association between high ITW intensity and positive perception of Prompt access to care is that ITW is aimed at improving care coordination by facilitating appropriate referral mechanisms to the relevant team member [49]. If this explanation is correct, our results would suggest that high ITW intensity has the potential to break down the "silos" in the health care system, reduce the barriers between multiple health professionals located in different settings (e.g., ambulatory oncology clinic, hospital, home care), and blur the arbitrary distinction between medical and psychosocial needs. Indeed, patients' positive perception of Prompt access to care is an important positive effect of high ITW intensity.

Positive perception of Quality of patient-professional communication was the second most positive effect of high ITW intensity documented in this study. Such communication is considered vital to quality patient care, particularly in oncology settings $[50,51]$. Patient-professional communication reflects the ability of a professional to listen to the patient, provide a clear response, and embrace a shared decision-making (SDM) approach. SDM is directly related to patient-professional dynamics. In the oncology field, high levels of satisfaction and confidence in treatment decisions are positively associated with SDM and are related to low levels of patient depression. These associations are independent of the patients' preferred level of participation (passive or active) in SDM [52]. On the one hand, patients report their symptoms and self-management activities to a team member who, in turn, provides additional information about treatment outcomes and shares the information with other team members. This information is valuable because it enables team members to tailor interventions to the individual by taking into account his or her specific characteristics and behavior patterns. On the other hand, it is well documented that poorly managed communication in the oncology field can result in unnecessary treatment and emotional distress for patients, thus negatively affecting their care experience $[51,53,54]$. This may explain why lower ITW intensity was less strongly associated with positive perception of Quality of patient-professional communication in our study.

The association between positive perception of Personcentred response and high ITW intensity in the context of cancer care was another important finding. Since the Institute of Medicine's seminal publication [55], the patientcentred approach has been considered the hallmark of high-quality care. Over the past two decades, patientcentred care has become internationally recognized as a dimension of the broader concept of high-quality health care, and many countries are now designing and implementing strategies and programs in this regard [56]. In a 
recent systematic review on cancer team effectiveness, only one study out of eleven addressed patient-centred care as an outcome indicator during active treatment. A qualitative multiple-case study completed with two interdisciplinary cancer teams from a Canadian teaching hospital reported that integrating patient values and preferences was still difficult for cancer care professionals, and patients were often expected to follow the rules established by professionals [57]. Bilodeau et al. concluded that two conflicting models shape the organization of oncology services: patient-centred discourse and professional-centred practice [57]. The association between high ITW intensity and positive perception of person-centred response may bring us to envision ITW as a way of accommodating the strengths of these two models, cancer care being seen as a professional service as well as a human relationship between patients and health professionals.

Our results indicate that patients receiving care in outpatient clinics with high ITW intensity are twice as likely to have positive perceptions of Continuity of care, compared to patients in clinics with low ITW intensity. Indeed, continuity of care is not simply about seeing the same health care professional at every visit; it is about perceiving that the interdisciplinary team uses all the information at its disposal (clinical and personal) for effective care planning. Health care professionals in teams with high ITW intensity tend to share the professional responsibility of oncology treatment and follow-up, offering more holistic patient care and allowing more opportunities to diagnose cancer recurrence. High ITW intensity involves paying attention to and anticipating the potential impact of cancer and its treatment, dealing with service silos, managing consequences for the whole person, and ensuring that important aspects of care have not been overlooked by the health professionals involved [58]. When professionals work together, attention can be directed to overcoming barriers facing patients, such as lack of knowledge of symptoms; late diagnosis and treatment due to fear; anxiety about disruption of work; child care problems; financial concerns; and unreliable transportation $[59,60]$.

Contrary to the conclusions of systematic reviews on ITW [5-7], we did not find an association between high ITW intensity and positive patient perception of Results of care. One possible explanation may be that the association between ITW intensity and perceptions of Results of care has multiple determinants, creating an indirect association. Other types of interventions, such as tumor boards focusing on therapeutic regimens, systematic symptom evaluations, and interventions by individual professionals, may act on the pathway between ITW intensity and patient-reported experience.

There was no association between high ITW intensity and positive perception of Quality of the care environment. Perhaps patients perceive the patient-professional- team relationship as having more importance than Quality of the care environment. Another explanation may be that basic amenities and professional courtesy are not directly related to ITW intensity. Some studies suggest that the responsibility to create a healing environment belongs all those working in a cancer setting, regardless of ITW intensity, and that this responsibility is embedded in complex relationships between professional practices, setting, and care providing processes [61].

\section{Strengths and limitations of the study}

A conceptual framework was used to ensure methodological transparency. Our measurements of interdisciplinary teamwork focused on both team structure and process items that characterize teams with high or low ITW intensity. We used the available validated instruments, which were cancer-adapted and had good reliability scales overall. No validated tool was available to evaluate ITW intensity in teams such as those in Quebec that include a diversity of professionals $[4,20,21]$. The general view in the literature is that the traditional criteria for scientific validity (e.g., internal consistency) do not by themselves guarantee usefulness to practitioners. Considering our pragmatic stance with the ITW tool, our work concentrated on content and pragmatic validity [62]. Pragmatic validity of knowledge can be judged by the extent to which intended consequences can be achieved by using particular instruments.

We thus carefully developed a measurement tool specific to oncology care. Although the tool is still under development, we used recognized procedures to ensure content validity evaluation [63]. The tool could be used in its current form to measure ITW intensities of other cancer care teams that are similar in size and include a diversity of professionals focusing on comprehensive patient-centred cancer care. However, it should not be used for interdisciplinary teams that are solely oriented toward medical treatments (e.g., cancer conferences or tumor boards). Potential misclassification of ITW intensity was mitigated by using information from the administrative database of the Ministry of Health and Social Services and interviews with frontline managers from each participating clinic [64].

Certain limitations may also be related to the PREMs scale. The tool used to measure perception of Results of care and Quality of the care environment was derived from the primary care sector. It is possible that it was not sufficiently sensitive to fully capture the effects of high ITW intensity, since all cancer teams work together to some extent. Finally, reliability (alpha $=0.64$ ) of the Quality of the care environment scale (alpha $=0.64$ ) was the lowest of all the scales used in the study, despite the fact that it was a cancer-adapted validated scale [26]. This may have reduced the ability to identify significant associations. Overall, it is difficult to compare our results with previous studies in the oncology setting $[5,40,65]$ 
due to significant differences in study design, the conceptualization and measurement of interdisciplinary teamwork, and the dimensions of patient-reported differences. Nevertheless, our study contributes to research aiming to provide evidence for the effects of ITW.

Whereas ex post facto quasi-experimental design is not optimal [19], it is important to realize that no other study design was possible, since ITW is already implemented to varying degrees in all cancer teams in Quebec [66]. Given the high response rate among patients, the diversity of organizational characteristics of the clinics that were included, and our careful assessment of ITW intensity, the results of this study could be generalized to patients treated and followed up in similar settings [67]. Finally, considering the characteristics of our sample, and because access to medical services is universal in Quebec, we feel cautious about generalizing our results to other health care systems. Nevertheless, our study has strong internal validity due to the robustness of its methodology.

\section{Conclusions}

Our quasi-experimental study makes an original contribution by demonstrating the association between interdisciplinary teamwork and specific critical aspects of the cancer care experience after adjusting for potential individual and organizational confounders. It represents an effort to produce evidence demonstrating the value and impact of team structure and teamwork processes in the context of cancer care. It also provides an original contribution to the measurement of interdisciplinary teamwork outcomes. Our study refines the portrait of what works in team-based care within the broader context of health care transformation. This is an important contribution considering that teamwork is a key concept promoted in most national cancer programs worldwide. Knowledge about the transformative capacity of teamwork requires further research to investigate more closely how teamwork contributes to a more positive experience, for whom and under what conditions. A better understanding of the association between teamwork and patient self-reported experience would have a positive impact on decisions related to the modernization of cancer services and help to better respond to the needs of cancer patients interacting with the health care system.

\section{Additional file}

Additional file 1: ITW tool components and Patient-Reported Experience Measures (PREMs) questionnaire items. Description: Table S1. presents the interview grid items to determine ITW intensity, criteria and indicator for quantification of qualitative data. In reference to the PREMs questionnaire used in the study, questions in Table S2. were designed to measure the cancer experience from the patient's perspective; questions in Table S3. were designed to document the sociodemographic, clinical, and organizational characteristics that were potential confounders. (PDF $106 \mathrm{~kb}$ )

\section{Abbreviations}

ITW: Interdisciplinary teamwork; OR: Odds ratio; PREMs: Patient-reported experience measures; SCP: Survivorship care plan; SD: Standard deviation; SDM: Shared decision-making

\section{Acknowledgements}

The authors wish to thank Elise de Castro Hillmann and Lise Lévesque for their contribution as research coordinators, and all personnel in the data-gathering units of the nine participating hospitals.

\section{Funding}

This study was supported by a joint Canadian Cancer Society Research Institute and Ministry of Health and Social Services of Quebec grant (Grant number: 020072). DT also receive salary awards from the Fonds de recherche du Québec-Santé (FRQ-S).

\section{Availability of data and materials}

The datasets analysed in this study are available from the corresponding author on reasonable request.

\section{Authors' contributions}

DT and DR designed, drawn the coordination and carried out the study. DT was responsible for drafting and reviewing the manuscript. NT participated in the design of the study, helped to analyze the data and reviewed the manuscript. EM participated in the design of the study, helped to analyze the data and reviewed the manuscript. DB participated in the design of the study, performed the statistical analysis and helped to review the manuscript. All authors reviewed and accepted the final version of the manuscript.

\section{Competing interests}

The authors declare that they have no competing interests.

\section{Ethics approval and consent to participate}

The study was approved by the Research Ethics Board of the Charles-Le Moyne Hospital Research Center (reference number MP-HCLM-09-050). Return of a completed questionnaire by mail was considered consent to participate.

\section{Consent for publication}

Not applicable.

\section{Publisher's Note}

Springer Nature remains neutral with regard to jurisdictional claims in published maps and institutional affiliations.

\section{Author details \\ ${ }^{1}$ Nursing School, Faculty of Medicine and Health Sciences, Université de Sherbrooke, Longueuil, Quebec, Canada. ${ }^{2}$ Charles-Le Moyne Hospital Research Center, Greenfield Park, Quebec, Canada. ${ }^{3}$ Department of Community Health Sciences, Faculty of Medicine and Health Sciences, Université de Sherbrooke (Longueuil Campus), Longueuil, Quebec, Canada. ^École nationale d'administration publique, Montreal, Quebec, Canada. ${ }^{5}$ Department of Social and Preventive Medicine, Faculty of Medicine, Université Laval, Québec City, Quebec, Canada.}

Received: 8 November 2016 Accepted: 16 March 2017

Published online: 20 March 2017

\section{References}

1. Borras JM, Albreht T, Audisio R, Briers E, Casali P, Esperou H, et al. Policy statement on multidisciplinary cancer care. Eur J Cancer. 2014;50(3):475-80.

2. American Society of Clinical Oncology, European Society for Medical Oncology. ASCO-ESMO consensus statement on quality cancer care. J Clin Oncol. 2006;24(21):3498-9.

3. Barr H. Interprofessinal education. Today, yesterday and tomorrow. A review. London: Higher Education Academy, Health Sciences and Practice Network, Kingston University; 2005.

4. Reeves S, Lewin S, Espin S, Zwarenstein M. Interprofessional teamwork in health and social care. Oxford: Wiley-Blackwell; 2010.

5. Taplin SH, Weaver S, Salas E, Chollette V, Edwards HM, Bruinooge SS, et al. Reviewing cancer care team effectiveness. J Oncol Pract. 2015;11(3):239-46. 
6. Prades J, Remue E, van Hoof E, Borras JM. Is it worth reorganising cancer services on the basis of multidisciplinary teams (MDTs)? A systematic review of the objectives and organisation of MDTs and their impact on patient outcomes. Health Policy. 2015;119(4):464-74

7. Gagliardi AR, Dobrow MJ, Wright FC. How can we improve cancer care? A review of interprofessional collaboration models and their use in clinical management. Surg Oncol. 2011;20(3):146-54.

8. Carey M, Sanson-Fisher R, Lotfi-Jam K, Schofield P, Aranda S. Multidisciplinary care in cancer: do the current research outputs help? Eur J Cancer Care (Engl). 2010;19(4):434-41.

9. Chamberlain-Salaun J, Mills J, Kim UK. Terminology used to describe health care teams: an integrative review of the literature. J Multidiscip Healthc. 2013;6:65-74.

10. Reeves S, Perrier L, Goldman J, Freeth D, Zwarenstein M. Interprofessional education: effects on professional practice and healthcare outcomes (update). Cochrane Database Syst Rev. 2013;3:CD002213.

11. Craig P, Dieppe P, Macintyre S, Michie S, Nazareth I, Petticrew M. Developing and evaluating complex interventions: the new Medical Research Council guidance. BMJ. 2008;337:a1655.

12. Tremblay D, Roberge D, Cazale L, Touati N, Maunsell E, Latreille J, et al. Evaluation of the impact of interdisciplinarity in cancer care. BMC Health Serv Res. 2011;11:144.

13. Croke JM, El-Sayed S. Multidisciplinary management of cancer patients: chasing a shadow or real value? An overview of the literature. Curr Oncol. 2012;19(4):e232-8.

14. Borrill C, West M, Shapiro D, Rees A. Team working and effectiveness in health care. Br J Cancer. 2000;6(8):364-71.

15. Poulton $B C$, West MA. The determinants of effectiveness in primary health care teams. J Interprof Care. 1999;13:7-18.

16. West MA, Borrill CS, Unsworth KL. Team effectiveness in organizations. In: Cooper $\mathrm{CL}$, Robertson IT, editors. International review of industrial and organizational psychology. Chichester: Wiley; 1998. p. 1-48.

17. Comité consultatif sur le cancer. Programme québécois de lutte contre le cancer. Pour lutter efficacement contre le cancer, formons équipe. Québec: Ministère de la Santé et des Services sociaux; 1997. http:// publications.msss.gouv.qc.ca/acrobat/f/documentation/1997/97-729-5.pdf. Accessed 2 Nov 2016

18. Comité des équipes interdisciplinaires de lutte contre le cancer. Les équipes interdisciplinaires en oncologie. Direction de la lutte contre le cancer. Québec: Ministère de la Santé et des Services sociaux; 2005. http://www. msss.gouv.qc.ca/sujets/organisation/lutte-contre-le-cancer/documents/ equipes interdisciplinaires_avis_aout2005.pdf. Accessed 2 Nov 2016

19. Cohen L, Manion L, Morrison K. Ex post facto research. Research methods in education. 7th ed. New York: Routledge; 2011. p. 303-11.

20. Kenaszchuk C, Reeves S, Nicholas D, Zwarenstein M. Validity and reliability of a multiple-group measurement scale for interprofessional collaboration. BMC Health Serv Res. 2010;10:1-15.

21. Canadian Interprofessional Health Collaborative [CIHC]. An Inventory of quantitative tools measuring interprofessional education and collaborative practice outcomes. 2012. http://ipe.utoronto.ca/sites/default/files/CIHC_ tools_report_Aug26\%202012\%20(1).pdf. Accessed 22 Nov 2016.

22. Rubio DM, Berg-Weger M, Tebb SS, Lee ES, Rauch S. Objectifying content validity: conducting a content validity study in social work research. Soc Work Res. 2003;27(2):94-104.

23. Tremblay D, Drouin D, Lang A, Roberge D, Ritchie J, Plante A. Interprofessional collaborative practice within cancer teams: translating evidence into action. A mixed methods study protocol. Implement Sci. 2010;5:53.

24. Roberge D, Cazale L, Tremblay D, Hébert-Croteau N. Les effets des équipes interdisciplinaires locales en oncologie au Québec : étude pilote en Montérégie. Longueuil: Centre de recherche de l'Hôpital Charles-Le Moyne; 2007. http://deslibris.ca/IDFR/253021. Accessed 30 Aug 2016.

25. Cazale L, Tremblay D, Roberge D, Touati N. La vignette: une stratégie novatrice pour apprécier la qualité des soins d'équipes interdisciplinaires en oncologie. Rev Epidemiol Sante Publique. 2006;54:407-20.

26. Tremblay D. La traduction d'une innovation organisationnelle dans les pratiques professionnelles de réseau : I'infirmière pivot en oncologie. [Ph.D. Thesis]. Montréal: Université de Montréal; 2007.

27. Caracelli VJ, Greene JC. Data analysis strategies for mixed-method evaluation designs. Educ Eval and Policy Anal. 1993;15(2):195-207.

28. The CONSORT Group. CONSORT Transparent reporting of trials. 2010. http:// www.consort-statement.org/. Accessed 30 Aug 2016.
29. Dillman DA, Smyth JD, Christian LM. Internet, mail and mixed-mode surveys: the tailored design method. 3rd ed. Hoboken: John Wiley Co.; 2009.

30. Valentine NB, de Silva A, Kawabata K, Darby C, Murray CJL, Evans DB. Health system responsiveness: concepts, domains and operationalization. In: Murray CJL, Evans DB, editors. Health systems performance assessment: debates, methods and empiricism. Geneva: World Health Organization; 2003. p. 573-96.

31. Tremblay D, Roberge D, Berbiche D. Determinants of patient-reported experience of cancer services responsiveness. BMC Health Serv Res. 2015;15:425.

32. Haggerty $J$, Roberge D, Freeman GK, Beaulieu C, Breton M. Validation of a generic measure of continuity of care: When patients encounter several clinicians. Ann Fam Med. 2012;10(5):443-51.

33. Pineault R LJ-F, Tousignant $P$, Beaulne $G$, Hamel $M$, Poirier $L-R$, Raynault $M-F$, Bénigeri M, Roberge D, Lamarche P, Haggerty J, Hanley J, Bergeron P, Dulude S, Marcil M. L'accessibilité et la continuité dans la population : l'influence des modèles d'organisation des services de santé de première ligne. Projet financé par la Fondation Canadienne de Recherche sur les Services de Santé. FCRSS RC1-1091-05. 2004.

34. Taplin SH, Anhang Price R, Edwards HM, Foster MK, Breslau ES, Chollette V, et al. Understanding and influencing multilevel factors across the cancer care continuum. J Natl Cancer Inst Monogr. 2012;2012(44):2-10.

35. Wagner EH, Aiello Bowles EJ, Greene SM, Tuzzio L, Wiese CJ, Kirlin B, et al. The quality of cancer patient experience: perspectives of patients, family members, providers and experts. Qual Saf Health Care. 2010;19(6):484-9.

36. Osborne RH, Elsworth GR, Whitfield K. The Health Education Impact Questionnaire (heiQ): an outcomes and evaluation measure for patient education and self-management interventions for people with chronic conditions. Patient Educ Couns. 2007;66(2):192-210.

37. Maunsell E, Lauzier S, Brunet J, Pelletier S, Osborne RH, Campbell HS. Healthrelated empowerment in cancer: validity of scales from the Health Education Impact Questionnaire. Cancer. 2014;120(20):3228-36.

38. Brunet J, Lauzier S, Campbell HS, Fillion L, Osborne RH, Maunsell E. Measurement invariance of English and French Health Education Impact Questionnaire (heiQ) empowerment scales validated for cancer. Qual Life Res. 2015;24(10):2375-84.

39. Hekkert KD, Cihangir S, Kleefstra SM, van den Berg B, Kool RB. Patient satisfaction revisited: a multilevel approach. Soc Sci Med. 2009;69(1):68-75.

40. Meterko M, Mohr DC, Young GJ. Teamwork culture and patient satisfaction in hospitals. Med Care. 2004;42(5):492-8.

41. MacCallum RC, Zhang S, Preacher KJ, Rucker DD. On the practice of dichotomization of quantitative variables. Psychol Methods. 2002;7(1):19-40.

42. von Elm E, Altman DG, Egger M, Pocock SJ, Gotzsche PC, Vandenbroucke $J P$. The strengthening the reporting of observational studies in epidemiology (STROBE) statement: guidelines for reporting observational studies. Ann Intern Med. 2007;147(8):573-7.

43. Salas E, Sims DE, Burke CS. Is there a "Big five" in teamwork? Small Group Research. 2005;36(5):555-99.

44. Walter F, Webster A, Scott S, Emery J. The Andersen Model of Total Patient Delay: a systematic review of its application in cancer diagnosis. J Health Serv Res Policy. 2012;17(2):110-8.

45. Neal RD, Nafees S, Pasterfield D, Hood K, Hendry M, Gollins S, et al. Patientreported measurement of time to diagnosis in cancer: development of the Cancer Symptom Interval Measure (C-SIM) and randomised controlled trial of method of delivery. BMC Health Serv Res. 2014;14:3.

46. Elliss-Brookes L, McPhail S, Ives A, Greenslade M, Shelton J, Hiom S, et al. Routes to diagnosis for cancer - determining the patient journey using multiple routine data sets. Br J Cancer. 2012;107(8):1220-6.

47. Weller D, Vedsted P, Rubin G, Walter FM, Emery J, Scott S, et al. The Aarhus statement: improving design and reporting of studies on early cancer diagnosis. Br J Cancer. 2012;106(7):1262-7.

48. Hammer MJ, Ercolano EA, Wright F, Dickson W, Chyun D, Melkus GD. Selfmanagement for adult patients with cancer an integrative review: an integrative review. Cancer Nurs. 2015;38(2):E10-26.

49. Littlechild B, Smith RS. A handbook for interprofessional practice in the human services: learning to work together. London: Pearson; 2013.

50. Sheldon LK, Hong F, Berry D. Patient-provider communication data: linking process and outcomes in oncology care. Cancer Manag Res. 2011;3(1):311-7.

51. Thorne SE, Bultz BD, Baile WF. Is there a cost to poor communication in cancer care? A critical review of the literature. Psychooncology. 2005;14:875-84.

52. Kane HL, Halpern MT, Squiers LB, Treiman KA, McCormack LA. Implementing and evaluating shared decision making in oncology practice. CA Cancer J Clin. 2014;64(6):377-88. 
53. Canadian Partnership Against Cancer. 2016 Cancer System Performance Report. Toronto (ON). 2016. http://www.systemperformance.ca/reports/. Accessed 30 Aug 2016.

54. Gaston T, Short N, Ralyea C, Casterline G. Promoting Patient Safety: Results of a TeamSTEPPS(R) Initiative. J Nurs Adm. 2016;46(4):201-7.

55. Institute of Medicine (US) Committee on Quality of Health Care in America. Crossing the quality chasm: a new health system for the 21st century. Washington (DC): National Academic Press; 2001.

56. Tzelepis F, Rose SK, Sanson-Fisher RW, Clinton-McHarg T, Carey ML, Paul CL. Are we missing the Institute of Medicine's mark? A systematic review of patient-reported outcome measures assessing quality of patient-centred cancer care. BMC Cancer. 2014;14:41.

57. Bilodeau K, Dubois S, Pepin J. Interprofessional patient-centred practice in oncology teams: utopia or reality? J Interprof Care. 2015;29(2):106-12.

58. King $\mathrm{M}$, Jones $\mathrm{L}$, Richardson $\mathrm{A}$, Murad $\mathrm{S}$, Irving $\mathrm{A}$, Aslett $\mathrm{H}$, et al. The relationship between patients' experiences of continuity of cancer care and health outcomes: a mixed methods study. Br J Cancer. 2008;98(3):529-36.

59. Lauria M. Continuity of cancer care. Cancer. 1991;67:1759-66.

60. Surbone A, Kagawa-Singer M, Terret C, Baider L. The illness trajectory of elderly cancer patients across cultures: SIOG position paper. Ann Oncol. 2007;18(4):633-8.

61. Hoybye MT. Healing environments in cancer treatment and care. Relations of space and practice in hematological cancer treatment. Acta Oncol. 2013; 52(2):440-6.

62. Worren NA, Moore K, Elliott R. When theories become tools: toward a framework for pragmatic validity. Hum Relat. 2002:55:1227-50

63. Rossiter JR. Content validity of measures of abstract constructs in management and organizational research. Brit J Manage. 2008;19(4):380-8.

64. Redfern SJ, Norman IJ. Validity through triangulation. Nurse Res. 1994;2(2):41-56.

65. Olsson M, Jarfelt M, Pergert P, Enskär K. Experiences of teenagers and young adults treated for cancer in Sweden. Eur J Oncol Nurs. 2015;19(5):575-81.

66. Direction québécoise du cancer. Bilan des réalisations des Orientations prioritaires 2007-2012 du Programme québécois de lutte contre le cancer. Quebec: Ministère de la Santé et des Services sociaux; 2012. http:// publications.msss.gouv.qc.ca/acrobat/f/documentation/2011/11-902-16.pdf. Accessed 30 Aug 2016.

67. Sitzia J, Wood N. Response rate in patient satisfaction research: an analysis of 210 published studies. Int J Qual Health Care. 1998;10(4):311-7.

\section{Submit your next manuscript to BioMed Central and we will help you at every step:}

- We accept pre-submission inquiries

- Our selector tool helps you to find the most relevant journal

- We provide round the clock customer support

- Convenient online submission

- Thorough peer review

- Inclusion in PubMed and all major indexing services

- Maximum visibility for your research

Submit your manuscript at www.biomedcentral.com/submit

) Biomed Central 